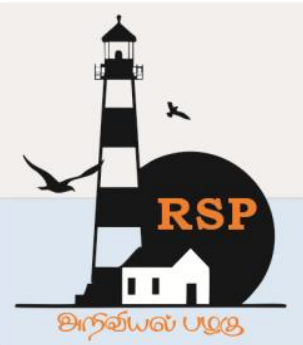

INTERNATIONAL RESEARCH JOURNAL ON ADVANCED SCIENCE HUB

RSP SCIENCE HUB

(The Hub of Research Ideas)

Available online at www.rspsciencehub.com

Special Issue of First International Conference on Engineering, Science, and Technology (ICEST 2021)

\title{
Modern tools in Agricultural Practices at Nagapattinam District - Field Realities
}

Dr. G. Sheela Edward ${ }^{1}$

${ }^{1}$ Assistant Professor, Dept. of History, TBML College, Porayar, Tamilnadu, India. sheelaedward897@gmail.com ${ }^{1}$

\begin{abstract}
Well-groomed farmers ready by accepting modern and smart agriculture Equipment. To increase income most farmers in India do farming through traditional methods, owing to which they find not as much of crop produce. As an effect, their profit starts reducing. At the same time, by farming with the help of modern resources and mechanical farming equipment the farmer increases his crop production. Uses of these modern farming tools will boost farmer manufacture and income. Nowadays, the farmers who are following smart farming are producing good profits by using the latest farming equipment equipped with new technology, which is raising their earnings. There are many innovations taking place to boost output and farmers cheer up in the fields of the farming sector. Modern farming machines help to increase significance and excellence of effort. Particularly new farming equipment is helping to supply improved; defend the public and atmosphere of the earth. Shortly we can say that new farming equipment is nothing but to reduce human attempt.
\end{abstract}

Keywords: Tillage tools, Transplanter, Weeder, Sprayer, Harvester, Hey Baler.

\section{Introduction}

Mechanization in farming is an effective way to utilize the inputs to raise the manufacture of property and labor. Moreover, it relieves the burden of farmhouse activities. The intrusion of technology into farming was profoundly prejudiced. As technology advanced, various farm machinery such as irrigation pumps, tillage machines, Chaff cutters, tractors and threshers were eventually introduced. The varieties that yielded the highest profits allowed farmers to begin using mechanical farm inputs, especially later than the Green Revolution in the 1960s. The progress of power threshing in 1960 with the inclusion of the Bhusa building attachment and the automatic sieves for grain and straw partition was the chief advancement that Indian engineers developed. Alternatively, the Farmers mainly adopted these threshers. Claim for other farm equipment such as reapers and combine harvesters before increasing the cost. Farmers have purchased irrigation, planting, harvest, and weed control equipment. Until now, farmers with smallholding have used a number of enhanced farm tools in the course of practice. Present farming automation is moving towards higher power equipment that can be bought on contract and daily recruiting.[1-6]

\section{Materials and Methods}

The analysis was conducted in the selected Nagapattinam villages of Vedaranyam, Keezhaiur, Nagapattinam, Sembanoarkoil and Mayiladuthurai. In these surroundings, the villages were chosen by assessment of a number of indicators specifically, overall farming growth, cropping greatness also discussed with ADA (Assistant Director of Agriculture), AO (Agricultural Officer) and AAO (Assistant Agricultural Officer) of the relevant 


\section{www.rspsciencehub.com}

village. Participatory Rural Assessment (PRA) was used to collect data on modern technologies, including how commonly they were used. Various main informants and progressive farmers addressing the subject in question were interviewed in conjunction with the sampling strategy. By surveying respondents using conventional mass communication approaches, the new techniques of farming and labour were recognised.[7-10]

\section{Results and discussion}

Modern tools used by farmers of these areas were recognized and described.

\subsection{Tractor mounted Mould board Plough}

Mower mounted plough can be powered by tractor. It comprises wood frame, share stage, and $\log$. It also includes log, frame and hitch organism. The bar type of share point encompasses different kinds of steel depending on its composition. Further, the share is made from varying steel composition ratios. The flashlights are tempered and hardened. The plough works through the operation of three-point attachment and hydraulic structure advantage to the soil. Its sharp tip makes it perfect for splitting wood.

It is used when planting soil. For the decomposing under the soil, it is also for turning green manure that adds humus to the soil muck, farmyard fertiliser or lime from spreading in the field, the mould panel plough is for turning and mixing these materials in the soil.

\subsection{Tractor Drawn Disc Plough}

The plough consists of discs geared together, a gauge wheel and a furrow wheel. In certain designs, the disc plough may act as two, three or four ploughs, by adding up or cancelling additional subsidiary parts. The disc angler ranges from 40 to 450 to acquire the preferred width of cut and the tilt angle ranges from 15 to 250 for entry. The discs of the plough are constructed out of stainless steel and the ends are sharp and hard. The tapered roller bearings are placed on the discs in difficult soils. Scrapers prevent dirt from piling up in the discs. To some degree before being thrown the
Volume 03 Issue $01 S$ January 2021

trough slice rides along the curving and is, pounded Uses disc plough is used for main tillage and is especially helpful in stiff and arid, shabby, rocky or stumpy land environment, and a major problem on soil where scouring.

\subsection{Spring Tyne Cultivator}

A frame cultivator, land wheel tynes, heavy-duty springsheavy-duty springs and a hitches system. To secure the tines of the plough when a few rough items come into contact with the plough or above the tines. In order to last for longer, the shovels are heat-treated. This tractor implement is a manually activated tool that relies on the hydraulic power of the tractor. Both in dry and wet soil Conditions are achieved by means of Cultivation. It is too used for intercultural purposes and to prepare puddling of crops.[11-14]

\subsection{Rigid Tyne Cultivator}

The assembly consists of rectangular rods, stacked rectangular bars, shovels and U clamps. It is a rotary tool. By changing the distance of the tines, it is possible to change the width of the lines. The spades are made of steel, and not aluminium or brass. The shovels are fixed on the tines with fastening sand, and can be quickly replaced when worn or damaged. The hydraulic system of the tractor, which accomplishes depth adjustment. For low tillage, or no tillage, the shovels can be replaced with pulled-type implements. Used to aerate and loosen soil and prepare seed beds for planting. Used for soil cultivation both in the subsoil and in stiff soils. It is suitable for cultivation on land because it is a duck foot shovel version. This means shipping and local farming.

\subsection{Bar Point Cultivator}

The cultivator is usually a rectangular frame with channels cut into it. With the use of clamps, rigidity is taken care of making the flat parts userfriendly. The ends of Tyne Bridge Bar points are joined. Bar links are made from any form of steel or carbon fibre. Other than bar holes, duck feet may also be connected to cultivators in place of the bar points. The cultivator is being used, the operator is turning the tractor. By pushing the 
cultivator forward and backward, it can be balanced vertically. By applying sand and other additives to light and hard soils for loosening intercultivation and seedbed preparations, aerating the soil, and cultivating subsoil. The duck foot shovel is suitable for cultivating in large, shallow plots.

\subsection{Peg Type Puddler}

The implement is tractor-mounted via the threepoint linkage made possible by a tractor. It is coated with wrapping made of steel angles. The cleats that are welded to the three crossbars are in the right place. It is used when the soil moisture is at the point of being spread to ensure smooth mechanical transplanting. The tractor is a part of its spokes. Used for rice transplanting and breaking up the soil clods.

\subsection{Land Leveller}

This is a tractor-mounted implement with three points of attachment, and which can be controlled hydraulically. The package consists of a hitch, mounting kit, cutting blade, and additional accessories. The blade is made of steel, and it has been hardened to achieve the right degree of elasticity. Dirt is scraped off the ground from the blade as the edge of the blade sticks into the ground allowing loose dirt to be extracted. The pitch of the levelling head is changed how appropriate. The leveller can be rotated to the left or right, or twisted upward to prevent overflowing the rear housing. Useful for washing up, irrigating, and terracing surfaces. It is used for a variety of grading and finishing tasks.

\subsection{Tractor Drawn Ridger}

The sugarcane farm where the windmill is located. It is a square frame made of mild steel angles nuts, bolts, and a ridge body. This body has two moulded portions, share, point and tie bars to distinguish the span of ridges. The share point is made of hardened and tempered steel, thin yet solid. By tractor, the ridgeline is dug into the soil, displacing soil from the ridge to the furrow, and then a furrow is created. The soil along the furrows has been compacted. The hydraulic system regulated the depth of the operation thus; the tractor. It is used in agriculture as a way of ploughing land.

\subsection{Tractor Mounted Subsoiler}

It consists of beams made of high carbons steel that are flanged at lower and upper ends for inflexibility, hollow steel adapter welded to the foot end of the beam to bring up hare bottom, share bottom having square part. A share shield made of high carbon steel and a shank drilled and countersunk in order to tightly protect the bottom of the adaptor. Share plate is carbon steel that is hardened and tempered for strength and durability. To render the bolt holes symmetrically positioned is there. Hydraulics and a relation between a tractor and an organism regulate the working depth of the subsurface. It loosens the soil by letting water flow through it, and improves drainage by allowing water to seep into the soil. A small tunnel can be dug in the ground after which a mole ball can be put on which, in turn, acts as a drainage channel for water.[15-17].

\section{Rice transplanter}

Rice transplanter is a specific transplanter built-in to transplant rice seedlings into paddy field. Two types of rice transplanter are riding variety and walking style. Riding style is power driven and can six lines in one pass usually transplant. However, the walking style is manually driven and four lines in one pass usually transplant. Rice transplantation is obtainable in a little sowing period; within period, it is critical to sow rice. A lot of hard work involves manual transplantation and takes more time. Human drudgery avoids the Mechanisation of rice transplantation and helps quicker rice sow. By maintaining plant-to-plant distance Rice Transplanter ensures accurate transplantation and to put in overall output number of seedlings per hill which helps better weeding and intercultural. For working in harsh wetland conditions a powerful $3.7 \mathrm{~kW}(5 \mathrm{HP})$ petrol engine used and evenly maintained the distance between the all rows. Especially for Indian farmers easy accessible controls are applied. Helps the farmer to save time for the fast speed of transplant. Robust device for better life span. While transplanting the Rubber lengthy days lugged wheels for enhanced 


\section{www.rspsciencehub.com}

traction. It helps to high hiring manual labour for a low charge of process. Low vibration level does not cause tiredness to the operator. For high yield for uniform depth, Automatic float adjustment mechanism is applicable. As if the seedling were taken between human fingers a regular rice transplanter combined a seedling plate like a shed cover on which mat style rice nursery is put, a seedling dish shifter that shifts the seedling tray similar to a cart of typewriters and plural pickup forks that pick up a seedling from mat type nursery on the seedling tray and put the seedling into the earth. Machine transplanting use rice transplanter requires significantly less time and labour than manual transplanting. It increases the estimated area that a person can plant per day from 700 to 10,000 square meters.

\section{Spray}

Particularly in conventional agriculture the most ordinary forms of pesticide function is the use of motorized sprayers. Hydraulic sprayers consist of a pump, tank, a nozzle (or multiple nozzles) and a lance (for single nozzles) or boom. Pesticide formulation changed by sprayers, frequently containing a combination of water and chemical compounds into droplets, which can be small about unseen particles or big rain-type drops. Under the force, this change is consummate by forcing the spray combination through a spray nozzle. Through application of diverse nozzle sizes the size of droplets can be changed or by varying the force under which it is forced, or a mixture of together. A pesticide application is the technical term for the manner in which a pesticide (including herbicides, fungicides, insecticides, or nematode control agents) is applied to its target (e.g. pest organism, crop or other plant). Public concerns regarding pesticide contamination have emphasised the need to minimise the amount of pesticides that are released into the atmosphere and human exposure (including operators, bystanders and consumers of produce).

With a harness, the back sprayers are fitted. Hence, the sprayers can be carried on the operator back. The capacity tank may be as large as 20 litres. To keep the pressures a hand lever is constantly operated. This makes backpack sprayers output more regular than that of a handheld sprayer. On
Volume 03 Issue 01S January 2021

commercial grade units of basic less cost backpack sprayer will cause only low pressure and lacking in features such as high-pressure pumps, pressure modification control (regulator) and pressure gauge set up. Most of the farmers in Nagapattinam district have been used in this type of sprayer.

\section{Weeder}

In the crops field weeding is the deletion of useless plants, it is very difficult to clean weeds successfully and completely. In a commercial farming system cutlass and hoe requires high labour force to remove weeds. This reduces human drudgery largely. The comparative higher output of operation by the weeder as compared to bullocks reduces the operational time and achieves timeliness in operation. It accounts for $80 \%$ of the farm holdings of the country that is ideally suitable to small farm holdings for mechanizing. Weeder should be an observable choice of smaller farmers by cost wise, for farm-operation if they are intending to have a mechanical power source. During operations as compared to by bullocks work Weeder reduces the hard work of collecting the unwanted grass between crops in the ground. During operation, weeder makes the manual of that unwanted grass by cutting it in small bits and carefully mixing it with soil. Automatic weeder is put in order to decrease drudgery implicated in manual weeding, it destroys the weeds and keeps ensuring loose surface soil aeration and power of water intake. The concern over ecological deprivation and an increasing requirement for organically manufactured foodstuff there is growing importance in the use of automatic intrarow weeders. Nowadays the farming zone requires non-chemical weed control that ensures food precautions. Consumers pay special attention to food safety and good quality foodstuffs. Too safely and sound food manufacture these mechanisms contribute considerably. Usually herbicides are used for weed controlling but due to ecological pollution even with the fact that herbicides contain many harmful effects. Mechanical weeding considerably improves weeding effectiveness as well as the excellence of weeding.

The equipment is generally self- guided. Functioning of the plan is a chain sprocket 


\section{www.rspsciencehub.com}

mechanism and engine that drives the wheels. It is expenses on field operations and a huge time saver. For weeding, it will have extremely powerful use on the farm ground. Growth of high capacity force proficient versatile machines and to increase labour output for combination of machinery, cost of operation reduced, timeliness of operation enhanced and appropriate for habitual hiring. Therefore, on the farm field either for weeding as well as for seeding is very useful. By the use of Mechanical weeder ecological deprivation and contamination caused by chemicals is reduced.

\section{Combine Harvester}

The current harvester is a combination of a wheelmounted harvester and a track mounted form. In agriculture, generating Yield is the popular labour demanding operation, which is fundamental to obtain the best yield. Delays in the harvest will have a widespread impact beyond just the crop; it will also affect the quality of the other goods being produced. The selling of the harvested and depleted natural resources are interlinked. For effective harvest of crops and grains, a combine harvester is a useful tool. The name of harvesting operations focused on four different processes of collecting, threshing, separating and winnowing. A combine is a combine harvester and grain cleaner. It completes threshing in a single phase. Our harvested crops are more consistent and productive. This helps farmers to harvest better quantities. With the manner of production, combine harvesters are divided into self-propelled and PTO-operated. Exact effort of a combine may be affirmed by Harvesting, Feeding of crops to the threshing machine, threshing the seed from the head, sorting out the seed from the rough ex-line, and clearing out the seed from the chaff.

It is harvesting, which means harvesting the plant from the ground. The crop is put in the header while the picker moves down the field. By a lift up roll which, too, retains the cut plants for further movement into the machine then the cutter bar that has teeth to cut the crop, which means mowing hands. Near the ground, these cut off the plants lower branches.

The next course of action consists of threshing the grain to isolate the different kernels. The crop is
Volume 03 Issue 01S January 2021

harvested after it has been cut, and is later carried into the combine harvester by a conveyor belt deposited into a threshing barrel. Within the threshing machine, the bars bang against the plant tops to separate the seeds from the straw or stems. As the grains fall down through the screen, straw walkers separate out the straw from the straw bales.

The cleaning system is able to use an air blow to remove the filth. The plants are gently dried and then gently blown with air. After separation, the grain is blown away and plant chaff is separated from the grain. Then they are moved into a receiving tank. When the collecting tank is loaded with grain, it is transported to the unloading machine from which it is moved to a trailer or storage container.

\section{Hay baler}

A baler is farm equipment used to compress a raked and cut crop (such as hay, straw, flax, cotton, marshy hay, silage or salt,) into packed together bales that are simple to transfer, hold, and stock up. Bales are configured to dry up and preserve some essential worth of the plants bundled bales are configured to dry up and preserved. Generally, various types of balers are in use. Every one produces a special type of bale cylindrical or rectangular of different sizes, twine bound netting and strapping.

Today Round baler is the most common type of baler in industrialized countries. It formed cylinder-sized rolled or round bales. It has a thatched roof model that affects the climate. Using fixed rollers rubberized belts, or a mixture of the two Grass is rolled up inside the baler. A prearranged volume reaches the bale; moreover, netting or twine is wrapped just about it to seize its figure. The bale is discharged after the back of the baler swings unlock. At this stage, the bales are complete, by a bale wrapper but they may possibly be wrapped in plastic sheeting, moreover to keep hay dry when stored outer or change damp grass into silage. Naturally created bales variable chamber big round balers as of 60 inches $(150 \mathrm{~cm})$ in width up to 48 to 72 inches (120 to $180 \mathrm{~cm}$ ) in diameter. Depending upon stuff size and content of moisture the bales can weigh somewhere from 1,100 to 2,200 pounds (500 to $1,000 \mathrm{~kg}$ ), 


\section{www.rspsciencehub.com}

depending upon size, material, and moisture content. Common small round balers (too called "mini round balers" or "roto-balers") produce 20 to 22 inches (51 to $56 \mathrm{~cm}$ ) in diameter and 20.5 to 28 inches $(52$ to $71 \mathrm{~cm})$ in width, generally weighing from 40 to 55 pounds ( 18 to $25 \mathrm{~kg}$ ).

\section{Backhoe Dozer}

Attachments for a field tractor. The dozer is behind the tractor and the backhoe in front. The dozer and backhoe can be disassembled and reassembled with the aid of the tractor. The dozer is composed of a defensive shield and a thick reinforced strip. The strip is fixed to the blade of the bulldozer by means of a pair of fasteners. As a result, the detached portion may be substituted on blunt wrappers. The dozer cover is connected to the tractor with a removable mechanical arm, which can be raised or lowered depending on the tractor's hydraulic system. A backhoe is a large machine used for digging with digging arms and a hydraulic cylinder that attaches to the tractor. The container is placed by a hyper-impaired hydraulic system. The rough fingertips can be substituted on tiring or blunted fingertips.

The backhoe is used to dig holes, create foundations, lay wire, clean garbage, widen stretches of road, and clear shrubs. Dozer is used for attacking ground levelling, making bunds in the farms and terracing of the farms, road making and site clearing, for trench filling at dam scheme, and afterward laying cable or pipe etc.

\section{Hydro dozer}

Dozer is a front-mounted mounted tractor. The dozer blade consists of a bent cover that supports a cutting edge, which is attached to the bucket with hydraulic cylinder, frame and body. The cutting plate edges are sharp and pointed, and are glued (not riveted) to the plate. A reversible type of blade is connected. The system is driven by hydraulics. It is used for building, earth forming, road construction, terracing, etc.

\section{Ditcher}

The cutting tip and blades are hardened, sharpened and machined from carbon or steel's alloy. The
Volume 03 Issue $01 S$ January 2021

ditcher is powered by a hydraulic system that is controlled by a tractor. Due to its heaviness and suction, the ditcher cuts the soil and in turn opens the form of a ditch, with either a ' $\mathrm{V}$ ' bottom or a flat bottom. Flight enhances the ditcher's ability to slice, roll, and brush through the difficult sod, brush, and root sets. The width and depth of the ditch is controlled from the operator's seat. The dozer's front and wings-facing cutting points and edges are replaceable. It is used in the construction of canals and drainage ditches.

\section{Conclusion}

We have found in our study that Nagapattinam district is much improved in case of involving modern farm equipment. Farmers of this district are relatively well informed and by means of new practice of agriculture. They are receiving advanced output and improved significance crops. In this region, farming through mechanical means has turned into an expected position where labour shortage is on the rise. However, at present the accessibility of new modern farming equipment are not extend equally. It is rented by big farmers and used by small and marginal farmers. What they are saying is that we have to pay between Rs. 2,000 and Rs.2, 500 as rent per hour. Therefore, modern machinery needs to be transported to long distances. Hence, our governments take in charge to make the machinery available locally to reduce the operation cost and facilitate timely harvest operation.

\section{References}

[1]. The Howard Rotavator". 2007-02-03. Archived from the original on 2013-06-06. Retrieved 2007-07-12.

[2]. Machinery Manufacturers - Secondary Tillage". Worldwide Agricultural Machinery and Equipment Directory. 2006-11-14. Retrieved 2007-07-12.

[3]. Singh, Gyanendra. 1999. Agricultural Engineering in 2000.Yojna, November43(11): 10-15.

[4]. Singh, Gyanendra. 2000. Modernization of Agricultural in India Part I Farm mechanization. Agricultural Situation in India. 
[5].Singh, G. and Bharadwaj, K.C. 1985. Directory of Agricultural Machinery and Manufacturers, Central Institute of Agricultural Engineering, Bhopal.

[6]. Agricultural engineering Britannica Online. Retrieved 2012-12-25.

[7]. Tractor (vehicle) Britannica Online. Retrieved 2012-12-25. Conklin, Alfred R.; Stilwell, Thomas (2007). World Food: Production and Use. p. 11. ISBN 9780470168714.

[8]. Constable, George; Somerville, Bob (2003). A Century of Innovation: Twenty Engineering Achievements That Transformed Our Lives, Chapter 7, Agricultural Mechanization. Washington, DC: Joseph Henry Press. ISBN 0309-08908-5.

[9].Biographical Dictionary of the History of Technology. Taylor \& Francis. September 2003. ISBN 9780203028292.

[10].The History of Combine Harvesters". Conway's

[11].CARROL J.: The World Encyclopaedia of Tractors \& Farm Machinery, 1999 Anne's Publishing Ltd, p. 127

[12].Farmindustrynews.com". Archived from the original on 2008-10-23. Retrieved 2009-11-1

[13].Machinery Manufacturers - Secondary Tillage". Worldwide Agricultural Machinery and Equipment Directory. 2006-11-14. Retrieved 2007-07-12.

[14].Howard, Arthur Clifford (18931971)". Australian Dictionary of Biography Online Edition. AustralianNational University. 1983. Retrieved 2007-07.

[15].Goodwin, Pat. "Buyer's Guide: Hay Equipment for Compact Tractors" (PDF). Retrieved 14 May 2015.

[16].Baler Guide - Two Ram Tough". Recycling Today.

[17].http://www.animaltraction.net/Harnessingandi mplements/HarnessingandImplementsintro. 